\title{
Application of satellites system based on different heights for ionospheric disturbances monitoring
}

\author{
Ivan Kaloshin", Vladimir Skripachev, Irina Surovceva, Vladimir Kuznetsov, and Alexander \\ Kharlamov
}

Moscow Technological University (MIREA), 119454 Moscow, Russia

\begin{abstract}
Results of data processing on-board Langmuir probes of CHAMP and DEMETER satellites are presented. The characteristics of satellites are given. Analysis of ionospheric parameters before strong earthquake is performed. At the altitudes of the satellites anomalous changes in the ionosphere parameters were detected a few days before the seismic event. Frequency distribution of anomalous ionospheric disturbances is obtained.
\end{abstract}

\section{Introduction}

Earthquakes are one of the most significant disasters for the people and the infrastructure of our country. In Russia more than $25 \%$ territory and near 20 million people could be exposed to the earthquakes with magnitude $M \geq 7.0$.

A lot of empirical material and researches of earthquakes precursors before earthquakes were collected for the last decades. It is known that earthquakes precursors appear in different geospheres, namely: lithosphere, atmosphere and ionosphere.

According to [1-3], ionospheric precursors observed up to several hours or days before an earthquake. Taking into account the ionosphere's variability, monitoring ionospheric precursors by satellites at different altitudes using identical onboard equipment has certain scientific interest.

\section{Data sources}

German satellite CHAMP has been working from July 15, 2000 to September 19, 2010, being in orbit with the altitude of $\sim 380 \mathrm{~km}$ and the inclination of $87.3^{\circ}$. French satellite DEMETER was launched to circular orbit with height $\sim 700 \mathrm{~km}$ and has been operational from June 29, 2004 to December 9, 2010. Figure 1 shows satellites relative position and idealized electron density profiles for day (solid line) and night (dotted line) ionosphere.

Satellites data were obtained from the web sites (http://gfz-postdam.de and http://cdpparchive.cnes.fr, respectively). Both satellites had Langmuir probes. They are one of the

\footnotetext{
* Corresponding author: kaloshin@mirea.ru
} 
effective instruments [4] to measure: $\mathrm{Ne}$ - electron density, $\mathrm{Ni}$ - ion density, $\mathrm{Te}$ - electron temperature (DEMETER satellite), and $\mathrm{Ne}$ - electron density (CHAMP satellite). Kp indices for analysis were obtained from the information on the web site http://omniweb.gsfc.nasa.gov.

For current study we have selected 12 earthquakes. Criteria of selection were: depth of epicenter of not more than $50 \mathrm{~km}$ and magnitude $\mathrm{M} \geq 6.0$, occurred in the period of satellites' operational activity (http://earthquake.usgs.gov).

Table 1 shows the List of the earthquakes selected in this research.

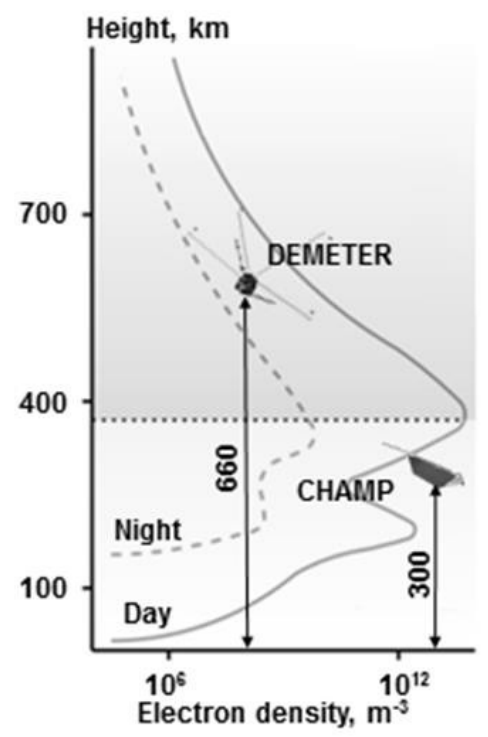

Fig. 1. Satellites relative position and idealized electron density profiles.

Table 1. List of the seismic events selected in this study.

\begin{tabular}{|c|l|c|c|c|c|c|}
\hline $\begin{array}{c}\text { \#Ca } \\
\text { se }\end{array}$ & \multicolumn{1}{|c|}{ Case study } & Date & Magnitude & $\begin{array}{c}\text { Geographic } \\
\text { latitude }\end{array}$ & $\begin{array}{c}\text { Geographic } \\
\text { longitude }\end{array}$ & $\begin{array}{c}\text { Dept } \\
\mathbf{h}, \\
\text { km }\end{array}$ \\
\hline 1 & Borujerd, Iran & 31.03 .2006 & 6.1 & $33.50 \mathrm{~N}$ & $48.78 \mathrm{E}$ & 7 \\
\hline 2 & $\begin{array}{l}\text { Kamchatka } \\
\text { Peninsula, Russia }\end{array}$ & 20.04 .2006 & 7.6 & $60.95 \mathrm{~N}$ & $167.09 \mathrm{E}$ & 22 \\
\hline 3 & Kuril Islands, Russia & 15.11 .2006 & 8.3 & $46.59 \mathrm{~N}$ & $153.27 \mathrm{E}$ & 10 \\
\hline 4 & Taiwan & 26.12 .2006 & 7.1 & $21.80 \mathrm{~N}$ & $120.55 \mathrm{E}$ & 10 \\
\hline 5 & Central Peru & 15.08 .2007 & 8.0 & $13.39 \mathrm{~S}$ & $76.60 \mathrm{~W}$ & 39 \\
\hline 6 & Antofagasta, Chile & 14.11 .2007 & 7.7 & $22.25 \mathrm{~S}$ & $69.89 \mathrm{~W}$ & 40 \\
\hline 7 & Xinjiang, China & 20.03 .2008 & 7.2 & $35.49 \mathrm{~N}$ & $81.47 \mathrm{E}$ & 10 \\
\hline 8 & Sichuan, China & 12.05 .2008 & 7.9 & $31.00 \mathrm{~N}$ & $103.32 \mathrm{E}$ & 19 \\
\hline 9 & Honshu island, Japan & 19.07 .2008 & 7.0 & $37.55 \mathrm{~N}$ & $142.21 \mathrm{E}$ & 22 \\
\hline 10 & $\begin{array}{l}\text { Minahasa Peninsula, } \\
\text { Indonesia }\end{array}$ & 16.11 .2008 & 7.4 & $1.27 \mathrm{~N}$ & $122.09 \mathrm{E}$ & 30 \\
\hline 11 & L'Aquila, Italy & 06.04 .2009 & 6.3 & $42.33 \mathrm{~N}$ & $13.33 \mathrm{E}$ & 8 \\
\hline 12 & Samoa Islands & 29.09 .2009 & 8.1 & $15.49 \mathrm{~S}$ & $172.10 \mathrm{~W}$ & 18 \\
\hline
\end{tabular}

Time period for data analysis was $[-60 ;+10]$ days around earthquake. Thus, 71 days were analyzed for each earthquake. 


\section{Processing technique}

After collecting the data available for our study, we have developed some calculation procedures to process them.

First step of processing satellite data was performed taking into account the zone of earthquake preparation, its size. Radius of earthquake preparation zone estimated using the formula $\mathrm{R}=10^{0.43 \mathrm{M}}$, where $\mathrm{M}$ is the earthquake magnitude. In defined radius data were classified by local time as day (06-18LT) and night (18-06LT) time. Afterwards data have been averaged.

Next, we used well-known technique that is based on the median value and the interquartile range. This technique detailed in the paper [5]. For obtained time series of average values we have calculated median value, inter-quartile range. These values were used to consider low and high bounds for each parameter (for both CHAMP and DEMETER data) by following formula:

$$
\text { Bound }=M \pm k \cdot I Q R,
$$

where $M$ - median, $k$ - coefficient which should be proportional to the earthquake magnitude. In this paper we used $k=1.5$ for all earthquake cases. All values outside bounds were considered as anomaly signals.

Figures 2 and 3 shows the results for Central Peru earthquake happened on 15.08.2007 with the magnitude $\mathrm{M}=8.0$. Day 0 corresponds to the earthquake day and is marked by dark arrow. Geomagnetic conditions were quiet in general.

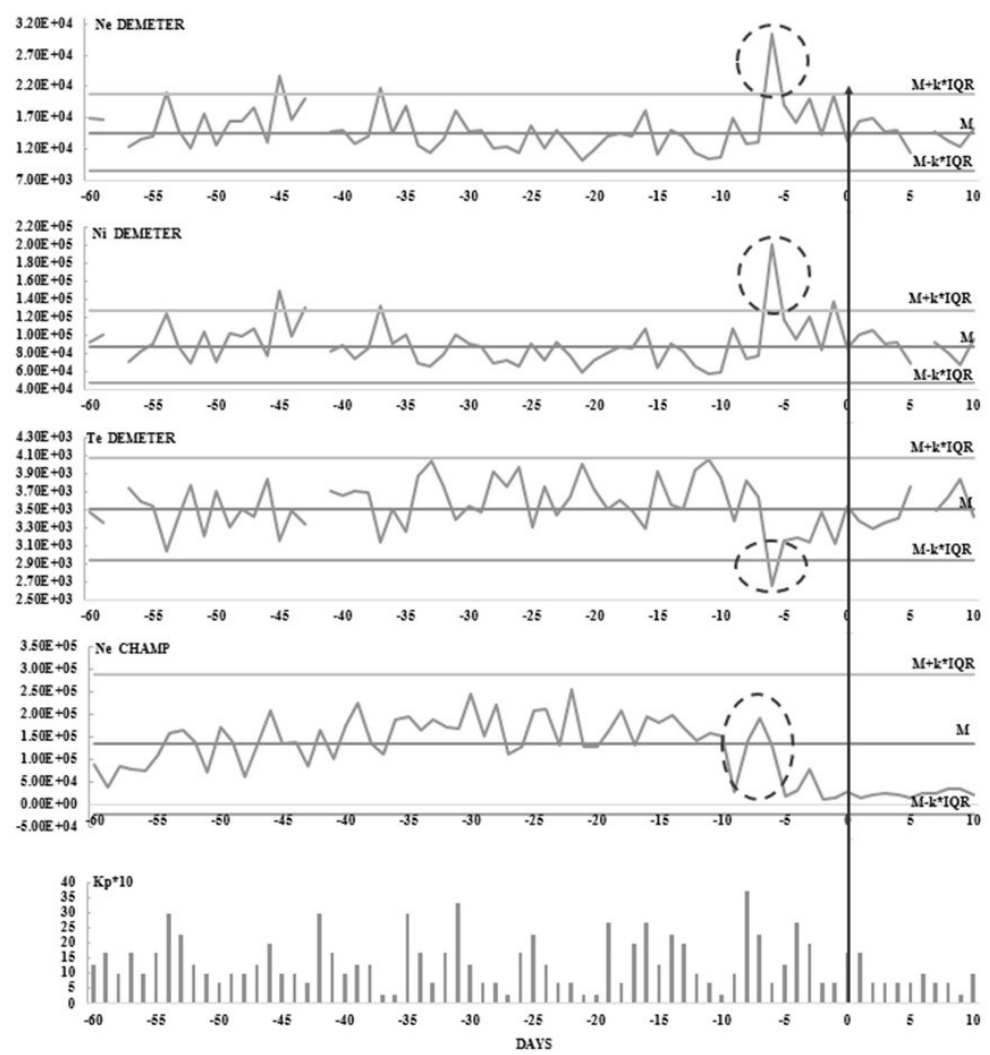

Fig. 2. DEMETER and CHAMP day time parameters and $\mathrm{Kp}$ indices. 
Note that $\mathrm{Ne}, \mathrm{Ni}$, and Te values increased up to $-7,-6$ days in the day time according to DEMETER data. For CHAMP data, Ne disturbances were not detected, but there is a significant increase by $-8,-7$ days. During the night time data processing for the DEMETER satellite, values of $\mathrm{Ne}$ and $\mathrm{Ni}$ increased by -10 and -9 days, as well as the growth of Te by -10 and -5 days was registered. According to the CHAMP data, there was the growth of Ne values, which began at -15 days with the formation of anomalies signals up to $-8,-3$ and -4 days.

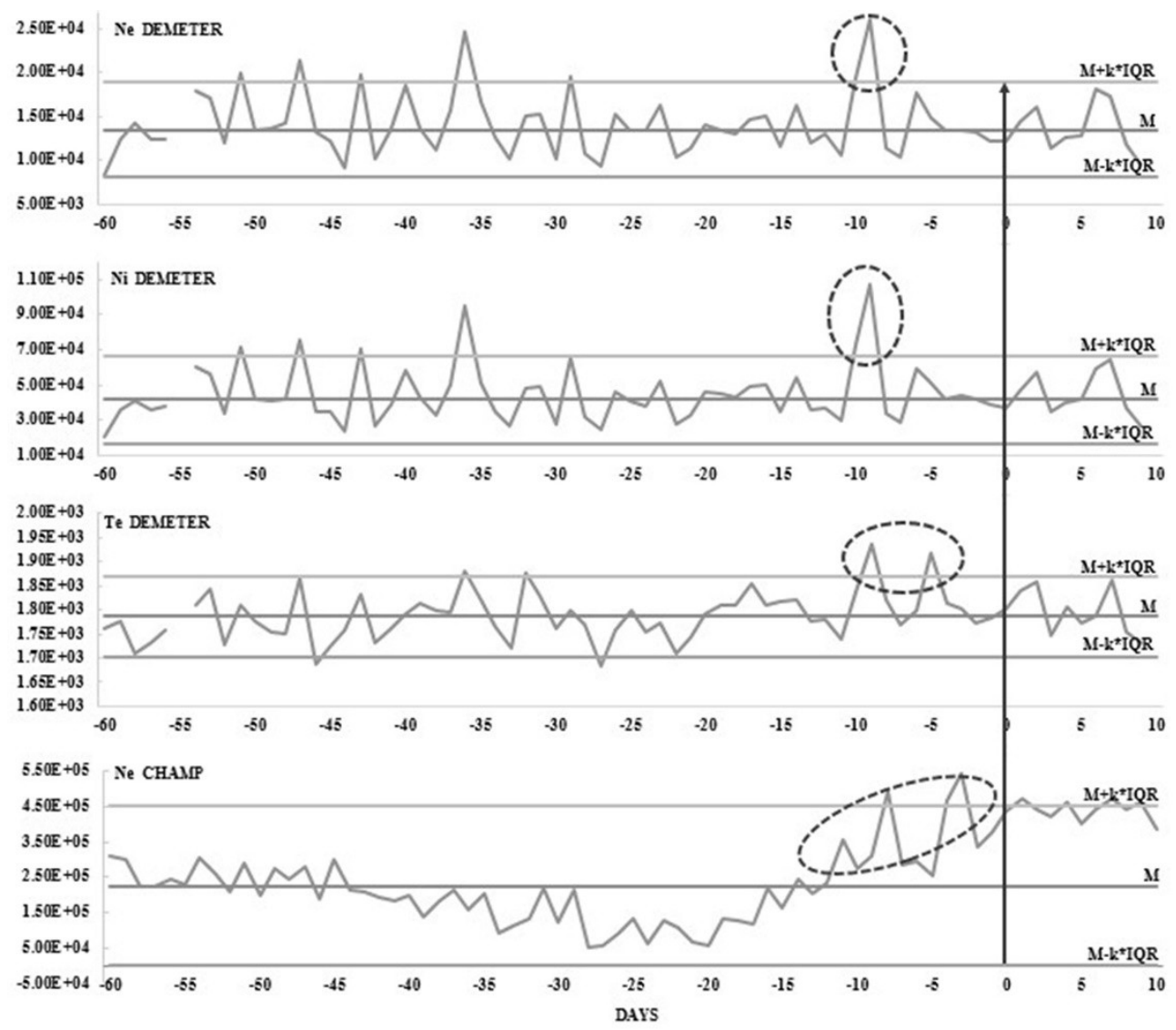

Fig. 3. DEMETER and CHAMP night time parameters.

\section{Results}

Described procedures have been implemented for all selected earthquakes. Results for all parameters were summarized in the Figure 4, which shows the frequency distribution of anomalous ionospheric disturbances. 


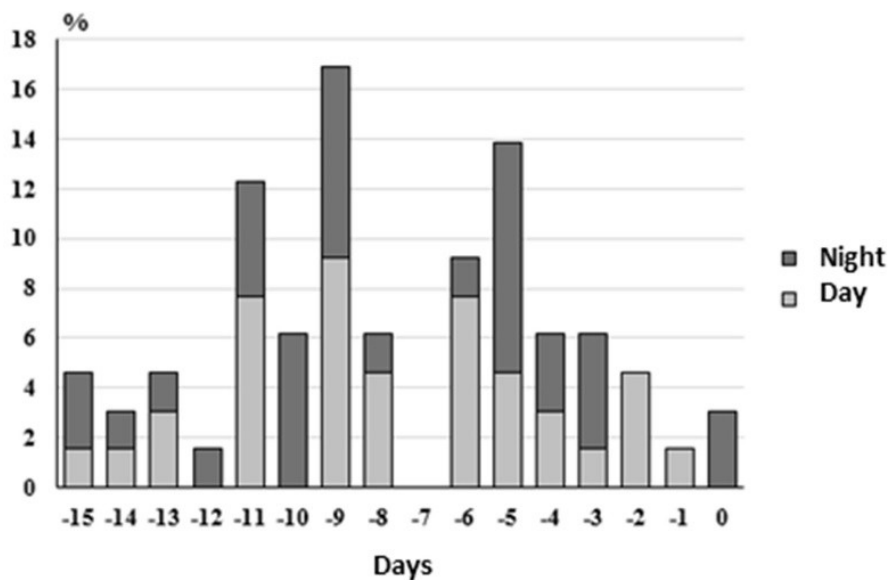

Fig. 4. Frequency distribution of appearance of anomalous ionospheric disturbances.

It should be noted that the greatest occurrence of significant variations was observed up to $-9,-5$ and -11 for daytime. It is noticeable also that the greatest amount of ionospheric disturbances for the studied earthquakes was observed in the period from -11 to -5 days. At first, the ionospheric disturbances, recorded during daytime, dominate, and then the predominance at night prevails. Attention is drawn to the fact that the disturbances at -7 days are absent.

\section{Conclusion}

Thus, we have performed the complex analysis of Langmuir probes obtained from CHAMP and DEMETER satellites. Our results are coherent with other studies, such as, for instance [4]. Simultaneous ionosphere monitoring at different altitudes could be useful by using serial small satellites.

The authors thank Centre des Données de la Physique des Plasmas (CDPP) and German Research Centre for Geosciences (GFZ) for the use of the DEMETER and CHAMP data respectively.

\section{References}

1. S. A. Pulinets, D. Ouzounov, D. Davydenko, A. Petrukhin, E3S Web of Conf. 11 (2016)

2. A. Rozhnoi, M. Solovieva, M. Parrot, M. Hayakawa, P.F. Biagi, K. Schwingenschuh, V.Fedun, Physics and Chemistry of the Earth, Parts A/B/C 85-86 (2015)

3. M. Parrot, V. Tramutoli, J.Y. Liu, S.A. Pulinets, D. Ouzounov, N. Genzano, M. Lisi, K.Hattori, A. Namgaladze, Nat. Hazards Earth Syst. Sci. Discuss. 172 (2016)

4. I. Kaloshin, V. Kuznetsov, V. Skripachev, I. Surovceva, MATEC Web of Conf. 102 (2017)

5. M. Akhoondzadeh, M. Parrot M, M.R. Saradjian, Nat. Hazards and Earth System Sci. 10 (2010) 